\title{
Airline Carriers E-Ticketing Mechanism Utilizing ONLINE RESERVATIONS MANAgEMENT SySTEM
}

\section{OMAMA SAMIR HeLmy \\ Higher Institute of Tourism Studies and Hotel Management (EGOTH), ALEXANDRIA, EgYPT}

\begin{abstract}
Many nations has seen a consistent advancement in technology over the last fifty years, with the advancements in each field made conceivable resulting in a high improvement in our personal lifestyle and overall comfort. Airline carriers have developed into a standout amongst the most complex and intriguing businesses of today. The carriers have made the fantasy of flying of the people into a reality in under a century. Today, a large number of individuals fly each day. This has fortified the economies of spots as well as associated individuals and societies. The headway of innovation has prompted enormous advance in the arrangement of flight ticket booking throughout the years.
\end{abstract}

Alongside globalization and the advancement of avionics industry, the procedure of ticket obtaining has additionally changed. Since the fast development and utilization of web in the 2000s, ticket buying has been conceivable on the web. Diminishing number of individuals is currently utilizing the conventional paper ticket while every significant carrier has given the likelihood of online tickets, generally known as e-ticket. A ticket today contains the data of the traveler's name, date of movement, the flight number, goal and beginning of movement, toll, charges, stuff data, administers on changes and discounts, type of installments, the legitimacy of the ticket, and other pertinent traveler information.

In this paper, the framework behind online ticket booking particularly utilized via airlines will be clarified. Different sources, for example, eBooks, online articles and sites have been eluded to accumulate the materials for the paper. The paper has been composed by containing data retrieved from the sources said above and showed with fundamental understanding. The topic has been picked because of the enthusiasm for the system of current flight booking process.

KeYwORDS: Airline Carriers, E-Ticketing, Mechanism Utilizing Online Reservations Management System. 


\section{MeTHODOLOGY}

The developed methodology consists of two parts: The process and applications of electronic ticketing and the administration of online reservations system. This methodology pinpoints the relationship between both applications and their relationships to enhance passenger processing.

While both are presented separately, the combination of both enhances customer experience and minimizes time constraints of processing passengers at airport terminals. This paper demonstrates how relationship of both improves the overall quality of passenger services and how constant technology adaptation can further improve efficiency and increase customer satisfaction.

\section{HYPOTHESIS}

This paper focuses on the impact of e-ticketing and how operational quality may positively influence a customer's choice of service provider. Customers are constantly looking for ways to improve their travel experience by minimizing delays through automation, and maximizing efficiency through online reservation systems.

Operational quality is defined in terms of characteristics such as consistency of service, accuracy of service, and service utility provided to customers (Schlesinger \& Heskett, 1997).

\section{Quantitative AND Qualitative Methods}

On average, people spend more time in electronic kiosks transaction rather than agent transactions. The decision to automate an airport facility is based on anticipated growth in demand. One cannot know with certainty what will happen in the future, the "true" state, but one can hypothesize and decide that growth will or will not occur.

Quantitative methods are, in general, supported by the positivist or scientific paradigm, which leads us to regard the world as made up of observable, measurable facts. In contrast, qualitative methods are generally supported by the portrayal of a world in which reality is socially constructed, complex, and ever changing.

Both qualitative and quantitative methods can be used differently in the same research projects. However, most projects and researchers place their emphasis on one form or another, partly out of conviction, but also because of training and the nature of the problem studied (Corbin \& Strauss, 2014). 


\section{THE SubJeCt OF THE STUdY}

An essential application like the models utilized via airline organizations today was produced with the utilization of different programming and projects. Research in sources, for example, e-books, web articles, and other documentation was comprised for the expansion of this paper. The paper reasoned that with the advance of regularly evolving innovation, the pattern of booking on the web is probably going to constantly develop and improve with as technology advances its overall highlights and features.

\section{The Aim OF THE STUdy}

The point of this paper is to clarify the arrangement of web based ticketing utilized via airline carriers by clarifying the component it uses. This paper likewise depicts the development and working of carrier's reservation framework.

\section{THE IMPORTANCE AND LIMITATIONS OF THE STUDY}

Different viewpoints identified with online flight booking are clarified in the paper. The primary focal point of the paper was building up a working utilization of the online airline ticketing process. While there are a couple of confinements, the accommodation of booking tickets on the web and the conceivable improvements will prompt a considerably further developed type of booking tickets on the web. Although we were able to collect data from various travel agencies and online references, we were unable to meet and interview direct employees of airline carriers or airport administrators.

\section{INTRODUCTION}

Throughout the years with the appearance of web, online ticket reserving for airline travel has been progressively prominent. The primary focal point of carrier organizations today has been in the fulfillment of clients. The organizations are doing this by making ventures conceivable in a completely versatile and social condition with the wise utilization of tremendous amounts of information to convey genuine administration and operational upgrades.

The customized utilization of cell phones and web by clients is required to increment radically, with the estimation of $90 \%$ airline organizations offering versatile registration by 2019 (Singh, 2008).

Web based business is the business exchange of merchandise and enterprises done over the web. With the coming of web, web based business has been developing quickly in the previous years. It is getting to 
be difficult to envision a world without internet business today. Numerous real business organizations around the globe presently offer their clients decision of choosing and purchasing the merchandise and enterprises at the solace of their homes. Different arrangements of correspondence and communication rules are utilized as a part of web based business as document exchange, email and shopping baskets.

Web based business makes it conceivable to purchase merchandise and enterprises round the clock which is conceivable from any piece of the world through a PC or other electronic devices such as tablets and smartphones associated with the web. Internet shopping isn't just more advantageous than the customary style of physically setting off to the stores, yet additionally offers a more extensive choice of items and great openness (Vincent, 2005).

Web based e-commerce business uses the electronic installment framework for the exchanges. The money related paperless framework has totally changed the substance of worldwide exchange due to its simple and advantageous offices, insignificant printed material on solicitations and negligible work and organization costs. The most widely recognized strategies used to pay online are credits cards, platinum cards, bank exchange and through different organizations, for example, PayPal. Because of the expansion in online business and its simple, bother free einstallment framework, numerous organizations, including the airline industry, have reliably become throughout the years (Wale, 2010).

\section{Airline Reservation System (ARS)}

Developing from manual records and logs in the mid-1930s, Airlines Reservations System (ARS) is the enhanced, mechanized element of carrier reservations. ARS helps in methodical and viable association of appointments, costs, calendars and client information. Carrier reservations framework has today developed into Computer Reservations System (CRS). ARS, when coordinated with Global Distribution System (GDS), can be utilized by various dissemination channels, for example, travel offices, which would then be able to utilize it for lodging rentals, flight booking, auto contracts and exercises and visits by means of single framework. ARS comprises of a few zones, for example, the stock administration, accessibility show and reservation and charge statements and tickets (Vincent, 2005).

The clients can undoubtedly buy an e-ticket by heading off to the ticket website, seeking and choosing the destination, entering the subtle elements, for example, name, method for flight, gear data and dates lastly 
making the installment by means of bank cards, bank exchange or through online payment option organizations. The e-ticket is then emailed or messaged on the phone of the client. While already travel operators and airlines helped clients in making ticket buys, today with the enhanced web framework, it is getting less demanding and simpler to book the flights without anyone in person or third party.

After the client makes the purchase, the electronic record and the points of interest of the ticket are spared into airline's database. The database is incorporated with the traveler benefit framework, which is then associated with the airports, airline carriers, travel offices for sharing actual time data (Mahadevan, 2009).

\section{Website Software and Programs Used}

Various programming soft wares have been utilized as a part of request to build up the internet booking framework. The kinds of projects and programming utilized were Python, Django, Hyper-Text Markup Language (HTML), Jinja, Javascript, Cascading Style Sheets (CSS), and SQLite Database. Appropriate establishments of the considerable number of projects utilized were required and fundamental understandings of the software were used in the culmination of the undertaking. Below is the breakdown of how the above mentioned software programs are utilized (Khair, 2013).

\section{PYTHON}

Python is a content programming dialect. Despite the fact that framework programming dialects, for example, $\mathrm{C}++$, Java and so on are very prevalent in school and school educational programs, Python is a propelled content programming dialect, which can be utilized as a part of numerous sorts of uses, is anything but difficult to learn and has easier language structure and semantics.

Scripting dialects are particularly appropriate for the basic programming grouping. Scripting dialects for the most part additionally have less complex grammar and semantics than framework dialects. Since Python contains bother free language structure rules, it energizes making of cutting edge applications inside brief time (Ni, Yi-Qing, 2012).

There is bunch of Python mediators accessible today which can be worked in different working frameworks. In the ongoing years, Python is a famous programming dialects and there are different perusing and practicing materials accessible (Vincent, 2005). 


\section{DJANGo}

Django is a web system intended for the improvement of simple but additionally propelled web applications. Django is created to support fast improvement and perfect, down to earth outline. A portion of the key highlights of Django are its help of fast web advancement, solid security and inspiring versatility. Django was the brainchild of World Online designers Adrian Holovaty and Simon Willison in 2003. As they created sites utilizing Django, they continually included new highlights which helped in creating rich, intelligent sites snappier and speedier (Wale, 2010).

Django consolidates the utilization of other open-source activities, for example, Apache, Python and PostgreSQL. Django is a successful programming apparatus to make rich sites. Since Django is a web system, it spares the designer time of making odds and ends from the scratch. Django is an accumulation of libraries written in Python dialect, and consequently coding in python is required for advancement in Django (Singh, 2008).

\section{HyPER-TeXt MARKUP LANGUAGE (HTML)}

Hyper-Text Markup Language (HTML) is a famous markup dialect utilized as a part of website pages. HTML can be just composed in a content manager and tried through internet browser. Writing in html is simple; with html it's likewise conceivable to add media and pictures to the site page. HTML contains uncommon markup labels like $\langle$ title $\rangle,\langle\mathrm{h}\rangle$, $\langle\mathrm{p}\rangle$ and so on. To announce the title of the page for instance, the title must be incorporated into the title labels. Also, the passages, headings and other distinctive substance in site pages must be incorporated inside the particular HTML labels (Irwin, 2008).

\section{JINJA}

Jinja is an easy to use, format dialect that utilizes Python. Jinja is comprised as the base for very intelligent site pages. It offers easy to use highlights, for example, sandboxed execution, layout legacy and configurable sentence structure. Linguistic structure of Jinja can be composed inside HTML format. Jinja is inferred correspondingly as Django. Effortlessness is a standout amongst other highlights of Jinja. Eminent organizations such Mozilla have utilized Jinja for their advancement. Jinja can be essentially composed in a content record, in any arrangement. The factors and articulations in layout get supplanted with values when format is rendered (Mahadevan, 2009). 


\section{JAVASCRIPT}

Javascript is a standout amongst the most mainstream content dialects for website development pages today. Javascript (JS) is a protest situated dialect that backings highlights, for example, basic and practical programming. The sentence structure is like other object related dialects, for example, Java and $\mathrm{C}++$, henceforth making it simple to learn for individuals who know these dialects.

JS is utilized to include intuitive highlights, for example, catches, movement, amusements and so on. JS was developed by Brendon Eich. Javascript is equipped for making various highlights extending from apprentice to cutting edge, for example, 2D and 3D includes on a site (Vincent, 2005).

\section{Cascading Style Sheet (CSS)}

CSS is a dialect that was created in 1992-1993. CSS helps outline every last component of the markup components dialect, for example, HTML by giving complete control to the originator. While the HTML components empower the website page fashioners to include what content they need, CSS makes it conceivable how to show the substance to the client. CSS covers the zones, for example, hues, format, propelled places of components, text styles and furthermore enables the substance to adjust the substance to various gadgets, for example, telephones, tablets, greater screens and printers. CSS can work freely and in addition be utilized with any markup dialects situated in XML (Ni, Yi-Qing, 2012).

At present, the essential highlights of CSS are upheld by every single principle program, for example, Internet Explorer, Safari, Opera, Chrome and Firefox. CSS has been utilized as a part of the website pages for the advancement of test web based booking framework for this theory for situating, design, edges and hues for the HTML components (Ni, YiQing, 2012).

\section{SQLiTe Database}

Databases are accumulations of comparative information. Databases are utilized for composed gathering and putting away of comparable information, to be later utilized for particular purposes. A database contains tables with lines and segments populated with objects, which shows association between them.

Databases are utilized all around: in little organizations which can utilize database to spare clients' data and furthermore for further developed logical and military zones. Databases encourage the assignment of 
seeking a large number of records considerably easier by putting away them in a sorted out way. Among numerous database programs accessible today, SQLite Database is the most normally utilized as a part of the improvement of e-ticketing process (Wale, 2010).

\section{FUNDAMENTAL FUNCTIONS AND IMPROVEMENTS USED IN APPLICATION}

The improvement of functions required utilizing numerous angles, for example, site planning and advancement, working with databases, working with rationales in programming dialects. Python and Javascript also utilize nearby server in Django to run, test and adjust the application. Fundamental information in such highlights and in addition is all the more learning along the advancement procedure expected to compose the functionalities. These fundamental highlights are expected to make any sort of sites or web applications. Some crucial highlights that are utilized as a part of the application improvement are quickly portrayed (Beaver, 2005).

\section{WEBSITE}

A website is a gathering of site pages. The data that is created by numerous sources is painstakingly composed, and made into documents and pages. It is then consolidated to shape a solitary substance called website. The information that is put away in the site is shown to the client with the assistance of various programming dialects like HTML, CSS and PHP. Sites are utilized as a part of online business, as wellsprings of data, showcasing, for creating connections and for amusement among others (Singh, 2008).

There are extraordinary strategies to rendering the web components to the client to influence it to look more pleasant and more composed which fall under the web planning region. For stacking sites, facilitated servers are required. The servers make it conceivable to exchange the pages to any internet browser through HTTP, the fundamental convention of WWW (World Wide Web). Site can be effectively gotten to by just writing the address at the address bar.

Most site names are anything but difficult to recollect and start with 'www'. In spite of the fact that there are endless assortments of sites out there today, there are regular components. Most, if not all, sites have a landing page, the main page that client sees after the page has stacked a route menu which contains other sub-pages and a footer territory with data, for example, contact, copyright data and others (Vincent, 2005). 


\section{WEB APPLiCATion}

A web application, as the name recommends, is an intelligent application in web. It is a gathering of numerous parts of HTML and other programming dialects, for example, servlets, html pages, classes and different assets. The application can be inside a site which is stacked by means of servlet when the address is entered (Irwin, 2008).Web applications are principally utilized for activity as opposed to data.

Web applications have abilities of using propelled gadget includes that it is utilized with. Web applications can frequently likewise work disconnected. Web applications are essential highlights of web innovation (Pedersen, 2011).

Anything that communicates with the client through the website page can be delegated as a web application. Web applications give various potential outcomes to organizations and comparable pages to cooperate with who is seeing their page. A basic overview installed in website page, or a bulletin information exchange shape, a login frame and a shopping bushel are for the most part cases of web applications. Web applications basically catch every one of the information, store and process them for additionally utilize. Web applications work inside layers: the principal layer is normally an internet browser; the second layer is the device that creates content or servlets and the third layer is the database that has the substance and additionally client information (Mahadevan, 2009).

\section{Web Designing}

Web designing is a basic part in the improvement of site and web applications. Web planning particularly is about the front-end of the page that the clients see. The fundamental part of any website pages is with two distinct things: one is with the front-end, which means what the clients can see and how they can communicate while the other one is the back-end of the page where every one of the information, functionalities and data are put away. A website specialist can outline how the page looks to the client utilizing essential markup dialects, for example, HTML among others (Belobaba, 2009).

\section{WEB DEVELOPMENT:}

Web advancement, or web writing computer programs, is a critical part of building sites and web applications by programming an arrangement of sensible guidelines to the PC. Programming dialects, for example, Java, Perl, PHP, C, C++, and ASP.NET are utilized as a part of the advancement of web applications. While website composition deals with 
the front-end of the site, web writing computer programs is in charge of the stuff that goes behind the perspective of the client (Belobaba, 2009).

The back-end highlights of any sites for the most part incorporate databases, content, rationales, cooperation of the pages and the improvement of uses. At the point when any page is opened in the program, the web serves parses and peruses the HTML page well ordered. When it goes over programming dialects, it will then actualize the code. Web writing computer programs is fundamental as it has the intensity of transforming straightforward and static HTML pages into a dynamic, client intelligent site with numerous highlights (Wale, 2010).

\section{The Design Stage}

The design blueprint of the application is imperative for quick and productive application advancement. An arranged format of the site was set up at first. Highlights, for example, framework outline, database plan and the way application was expected to work must be remembered before beginning the usage. In the wake of downloading the fundamental stages and projects for execution and finding out about the highlights that were wanted to join in the application, the usage procedure began (Belobaba, 2009).

\section{SYSTEM DESIGN}

The online ticket framework utilizes customer/server engineering. In customer/server figuring model, a server has, gives and deals with the assets and administrations made for the customer. This sort of model typically has in excess of one customer PCs associated with focal server over web association. All solicitations and administrations are conveyed over the system in this model and the framework shares assets. The web itself is likewise in view of this engineering (Singh, 2008).

In online ticket booking model, a customer can utilize an internet browser to get to the site and book online tickets. It is anything but difficult to make the booking as the framework is easy to understand. The greater part of the code is composed in Python as Django stage is utilized. At the flight seek inquiry, when the client looks favored decisions, the web server scans the database for likenesses and returns the outcome in client meaningful shape. After the client books the choice and the installment is confirmed, the information of customer is spared to the organization's database. Contingent upon the choice, clients are sent an e-ticket or SMS affirmation. In the example application made for this paper, clients are basically sent the e-ticket to their email address subsequent to booking (Belobaba, 2009). 


\section{Database Design}

The database utilized as a part of the application is SQLite which comes introduced with Django bundle. The information is separated into three principle parts named Connection, Feedback and Ticket. In the tables under Connection, there is information, for example, place of cause, place of goal, takeoff time, entry time, date, value, seats accessible and flight name. The data in Connection was physically coded. The Feedback segment is loaded with the client's name, email address and plan when he/she leaves a criticism or message on the page through the contact shape in the site. The ticket segment contains the schedule of the customer after he/she has made the booking. This segment contains data like the individual subtle elements of client, for example, name, last name, birth date, nationality and the booked flight points of interest. This data is later used to make ticket and send it by means of email to the customer (Irwin, 2008).

\section{The Website AND ITs LogiC}

For this paper, we've created an imaginary company called "ABC Airlines. This non-existent carrier is situated in the United States and services flights between countries. The site of the organization is straightforward. There are five subpages which are anything but difficult to explore through the file. The foundation and straightforward text style is the same in every one of the pages. Once the client goes into the page, he/she can locate the landing page, where there is some current news about the organization and additionally the principles. Other than home, alternate subpages are named "Flight Search", "About Us", "Charges and Regulations" and "Contact" (Belobaba, 2009).

The principle usefulness of the application lies in the page called "Flight Search" where the client can make flight reservations. The design is extremely straightforward: client can choose the place of starting point and place of goal alongside the favored date of flight. There is alternative to check the case for one way flight or enter the arrival date for two way flight. The client likewise needs to indicate the quantity of grown-up tickets as well as youngster and newborn child tickets. Every one of the fields aside from one way checkbox, kids and baby ticket are obligatory (Xu, 2010).

\section{The Website Pages}

On this example of the fictitious airline ABC Airlines, the site has five principle pages which can be explored by the basic list. The client first terrains on the landing page; Landing page has content like recent news 
about the organization, and connections to different subpages. Also, pages 'About' and 'Contact' hold the data about the organization and contact points of interest individually. In 'Contact' page, the client can influence utilization of the criticism to frame to send message to the organization. In 'Admissions and directions' page, the client can discover data about the strategies of the organization with respect to tolls and controls. There is 'Flight Search' page from which the client can seek flights and continue to reserve a spot. But 'Contact' and 'Flight Search' pages, the staying three principle pages are static. Diagram 1 demonstrates the fundamental website pages and sub-pages of the application (Wale, 2010).

Figure 1 Web pages and subpages



Source: (Singh, 2008)

The application is produced with the point of showing and figuring out how the flight booking framework functions. SQLite database is utilized for capacity of information. After entering the landing page of the site, the client has alternative to seek flights. The client needs to just choose the place of inception and destination, alongside date and number of travelers. The client additionally has choice to look return trip for a similar way. In the event that no flight or return for precisely the same is discovered, the ones that are accessible are shown in the outcomes. Clients can choose their preferred associations from the outcomes enter their contact email for confirmation delivery and continue to booking (Singh, 2008). 
In booking page, clients can enter their own points of interest, for example, name, birthdate, nationality and sex. Close by the booking structure, the flight points of interest that they have booked are shown. In the wake of rounding out the points of interest, the clients can basically tap the "Confirm Reservation" icon after which they will get an e-ticket on their email address (Xu, 2010). On the application backend, when search inquiry is submitted for flight, the data from Django platform is saved and verified in the database.

In the event that the chose flight way for the correct date isn't discovered, at that point the association for accessible dates is shown. At the point when the clients have affirmed the reservation and entered their email address, the e-ticket with the flight subtle elements that was saved on session alongside the individual points of interest through Django platform and is sent by email to the clients. The individual details entered by the client are stored in the database of the airline's administrator page (Vincent, 2005).

\section{The Development Stage}

Despite the fact that the development stage is a straightforward web application, it included working with various projects and their highlights. Subsequent to settling on the general arrangement of the application, every one of the projects that were essential was introduced accurately. The application procedure was completed and numerous new systems and highlights were found out amid the process from different sources. Alongside programming, the procedure additionally included continuous testing and changing to create the coveted form in application. The fictional airline carrier is named as "ABC Airlines," that is a U.S. - based carrier offering connections between countries (Belobaba, 2009).

\section{SETTINg UP DJANGo FraMeWORK}

The application was created with Django web system and was composed in Python programming dialects. Django has segments that cooperate in various regions. The SQLite database that is utilized as a part of the application is upheld by Django and comes introduced with the bundles. To begin the undertaking, it was vital to have designed Django modules legitimately $(\mathrm{Xu}, 2010)$.

Diagram 2 demonstrates the Django architecture. The URL dispatcher tracks the asked for URL in the view work, which at that point does a few tasks and returns an incentive through characterized layout. Perspectives work regularly includes perusing, composing or getting from the database, however can likewise perform different activities. The model 
characterizes the information in database and interfaces with it. In Django, databases, for example, MySQL and SQLite are frequently utilized yet Django is equipped for supporting different databases as well. Layouts are normally HTML pages. At the point when sees module runs the capacity, it returns result in format, which is then shown in the characterized html page to the client (Belobaba, 2009).

\section{Figure 2 Django Architecture}

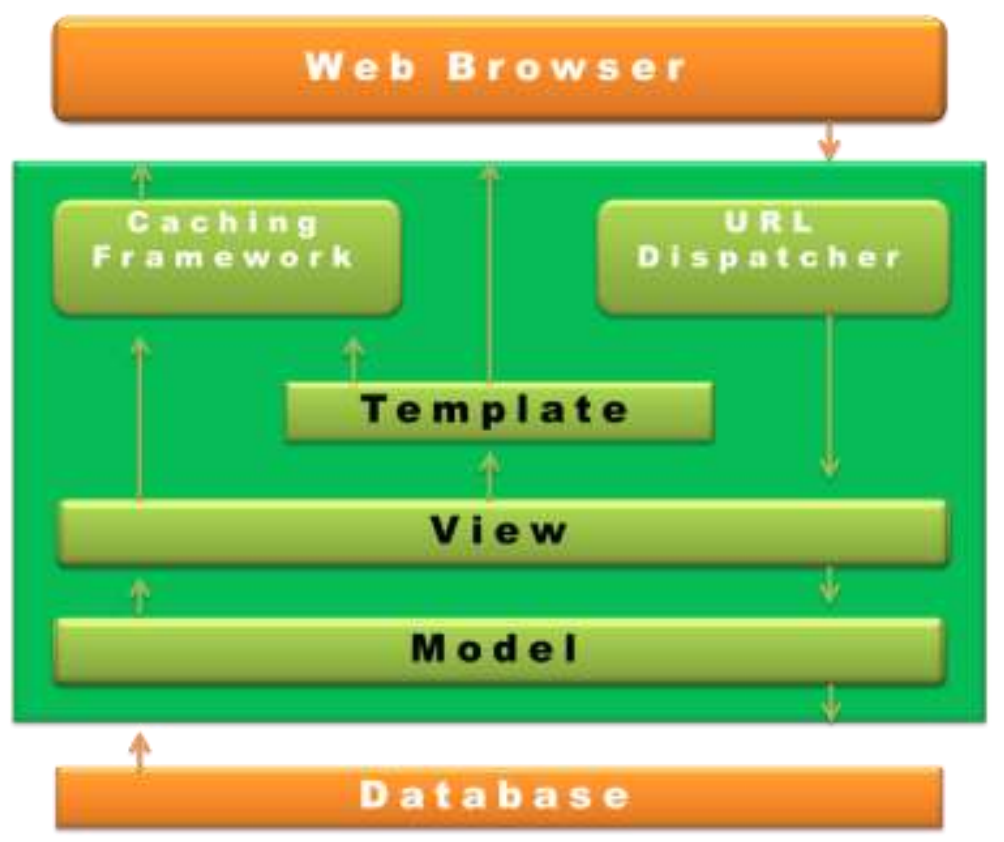

Source: http:// docs.djangoproject.com/en/2.0/faq/general/

\section{Creating Admin User}

Django gives the likelihood of making an administrator client, who approaches all the substance of the site. This authorization is just for the site directors who have the specialist to alter, include and erase content. The administrator client can likewise observe and alter the database. Administrator access is made in Django shell. Client and secret word are set up which is later used to sign in to the administrator part of the page. Diagram 3 demonstrates the administrator board. It demonstrates the administrator perspective of the application where the administrator can change, include and erase content physically (Belobaba, 2009). 
Figure 3 Admin view

\section{DjangoAdministration}

\section{Site Administration}

Authentication \& Authorization

- Groups

- Users

\$Add $/$ Change

\&Add Change

\section{ABC Airlines_App}

- Connections

- Feedbacks

- Passengers

* Add $>$ Change

\$Add $>$ Change

\$Add $>$ Change

Source: https://docs.djangoproject.com/en/2.0/ref/contrib/admin/

\section{Making Static Web Pages}

A file with five fundamental pages: "Home", "Flight Search", "About", "Fares and Regulations" and "Contact Us" is made with uniform outline and CSS in all pages. The list page goes about as a primary page for the various subpages. The plan and design of the sub pages are the same as file page. The five primary pages named "Flight Search", "About", "Contact Us" and "Fares and Regulations" are consequently inserted with the itemized page (Vincent, 2005).

The landing page is shows static substance about ongoing news of the organization, short data about airport exchange and baggage regulations. The landing page is the principal page that the client sees when opening the site. Under the data about airport terminal exchange and baggage regulations, there are joins coordinating to particular pages. For the pages "Home", "About" and "Fares and Regulations", some data in content is included (Xu, 2010).

\section{USer-interactive Pages}

The two primary pages that are client intuitive are "Flight Search", where the clients can hunt and book flights and "Contact Us" page where the client can see the contact data about the organization and in addition send input through feedback form. The form entails three fields where the 
clients can enter their name, email address and message. The information from Feedback Form subsequent to sending is spared into organization's database (Belobaba, 2009).

Through "Flight Search" page, other intuitive pages open. The principal intuitive sub-page is for flight selection, where the clients can choose the departure from comes about and enters their email address. The second intelligent sub-page is flight booking, where the clients need to enter their own points of interest keeping in mind the end goal to confirm the booking (Xu, 2010).

The search page contains various components. The client can search flight associations by completing the fields with entries. The platform is shown as a passage in a basic design. The information that clients enter is sent to the server and is spared in sessions which are utilized later to book and prepare the e-ticket (Belobaba, 2009).

\section{The Methodology for Receiving An E-TICKET Via EMAIL}

The capacity for sending e-ticket to the email address put together by the client is executed after the submission icon button. The individual information from the client through frame sets is spared in the database and the flight subtle elements spared in session are utilized for setting up the e-ticket. The email to the client is sent by means of python's module (Pedersen, 2011).

\section{SENDING E-TICKET}

The e-ticket contains the traveler subtle elements brought from database and the flight that they picked. The capacity for sending e-ticket is naturally activated after the client presses "Confirm Reservation" icon on "Book Now" page. The e-ticket is sent as plain content as appeared in Diagram 4 to the email address of the client (Xu, 2010). 
Figure 4 E-ticket received in customer email

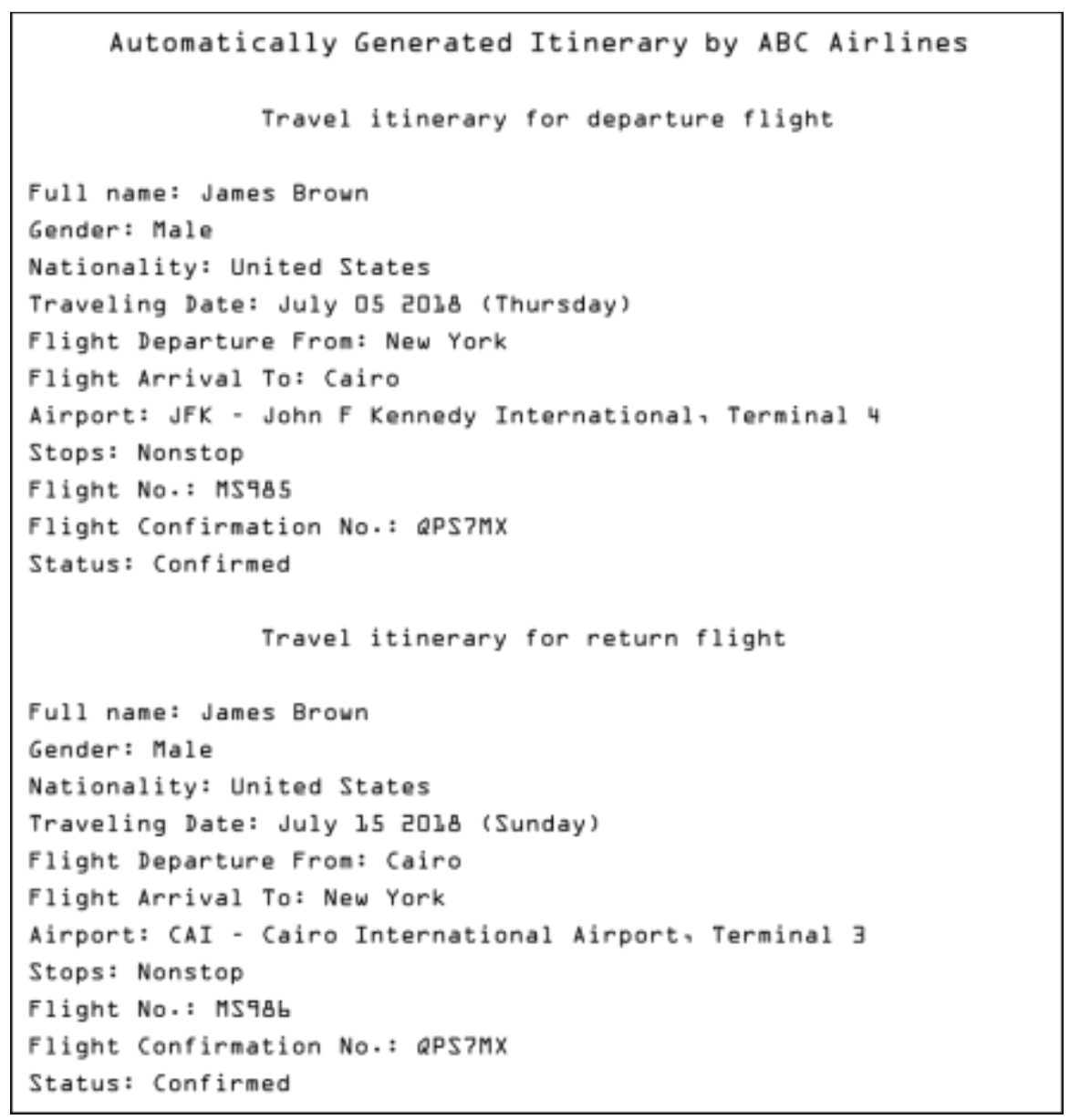

Source: (Joaquin Garcia-Alfaro, 2011)

\section{CONCLusions}

Technology has changed the way consumers shop for airline travel. The conventional tickets on the beginning of air travel were made of paper and were to be gathered from the travel offices or airline office subsequent to acquiring. E-ticketing had changed the way we obtain travel vouchers. It provides proof of the acquisition and the verification of a reserved seat on the plane for the desired destiny.

Although E-ticketing had greatly improved the way consumers shop, technology continues to evolve with the objective to improve the overall consumer's shopping experience.

It allowed consumers to shop airlines either directly through the airline carrier's site or through a third party site such as Kayak, Expedia, 
Booking, Travelocity or many others if they're shopping for the lowest fares.

With the convenience of E-ticketing, consumers are able to bypass conventional methods of travel agencies or airline ticketing offices and buy directly online in the convenience of their own home and time.

The overall consumer shopping experience and airline's passenger processing will continue to improve and evolve as technology continues to pave the way for airlines to integrate other advanced methods.

The world has progressed into the period of web innovation. The airline carrier business influenced utilization of the web to its optimum by creating airline reservation framework (ARS), which has now advanced into Computer Reservation System (CRS). Utilizing the CRS innovation now, it is effectively conceivable to book flights online through the airline sites or through outsider third party sites.

Although current customers come from developed countries with high speed internet access, developing countries are in the progress to catch up and eventually gain momentum for this service. The web security and the constrained clients from just the created side of the world are right now the greatest general difficulties. Yet, since different research and results demonstrate that the matter of airline carriers has expanded by folds upon the presentation of online flight booking framework, it is relatively sure that there will be further improvement and upgrade in the as of now easy to understand online arrangement of most carriers today with the quick development of innovation.

\section{RECOMMENDATIONS}

There is no arguing that the airline's online reservation system is here for the long haul. It can be anticipated from the carriers businesses as well as other travel and tourism enterprises to include significantly more highlights and improve the online arrangement of booking and different applications.

So what's next? The absolution of boarding passes is one alternative. Once a system has been adopted that would delete boarding passes completely, consumers will greatly enjoy further improvement of checkin systems and faster boarding experience, making it more efficient for passengers, and airline carriers can retain higher customer satisfaction.

There are many aspects still to be assessed regarding the implementation of an electronic ticketing system. The following alternatives can be 
considered to further improve the passenger flight experience and processing:

- Improve passenger data collection through automation

- Improve working conditions for airport operators

- Find ways to improve and reduce boarding time experience

- Apply further automation of passenger processing that will help reduce costs

- Initiate a bar coding system that can eliminate hard copy of boarding passes

- Enable passengers to print an e-ticket from their personal computer

- Continue to find ways to reduce document distributing costs

- Enhance passenger check-in options

- Find ways to further improve on board verification and control process

- Intergrade a user friendly online systems for a better shopping experience

- Improve overall efficiency and image of airline transport network

\section{REFRENCES}

Beaver, Allan (2005). A Dictionary of Travel and Tourism Terminology, CABI Publishing Series, CABI.

Belobaba, Peter (2009). The Global Airline Industry, Aerospace Series, John Wiley \& Sons.

Corbin, Juliet \& Strauss, Anselm: (2014). Basics of Qualitative Research: Techniques and Procedures for Developing Grounded Theory, SAGE Publications.

Irwin, Richard L., (2008). Sport Promotion.

Khair, Nor Safura (2013). iConsumer Behaviour in Using Airline Eticketing in Malaysia, Fakulti Sains Komputer dan Sistem Maklumat, p. 88.

Mahadevan, B. (2009). Operation Management: Theory and Practice, Pearson Education India.

Pedersen, Paul Mark (2011). Contemporary Sport Management, Human Kinetics.

Schlesinger, Leonard A. \& Heskett, James L. (1997). Service Profit Chain, Illustrated, Simon and Schuster.

Singh, L.K.: (2008). Foreign Exchange Management and Airline Ticketing, Gyan Publishing House 
Vincent, J., (2005). RT Essentials, Essentials Series, System administration, O'Reilly Media, Inc.

Wale, Debra (2010). Events Management, CABI Tourism Texts.

$\mathrm{Xu}$, Jun (2010). E-Business in the 21St Century: Realities, Challenges and Outlook, Intelligent information systems, World Scientific.

Ni, Yi-Qing, (2012). Proceedings of the 1st International Workshop on High-Speed and Intercity Railways, Lecture Notes in Electrical Engineering, Springer Science \& Business Media.

Joaquin, Garcia-Alfaro, (2011) Data Privacy Management and Autonomous Spontaneous Security: 5th International Workshop, DPM 2010 and 3rd International Workshop, SETOP, Athens, Greece, September 23, 2010, Revised Selected Papers LNCS sub-library: Security and cryptology, Springer Science \& Business Media.

http://www.mytardis.org/ https://www.djangoproject.com/ 